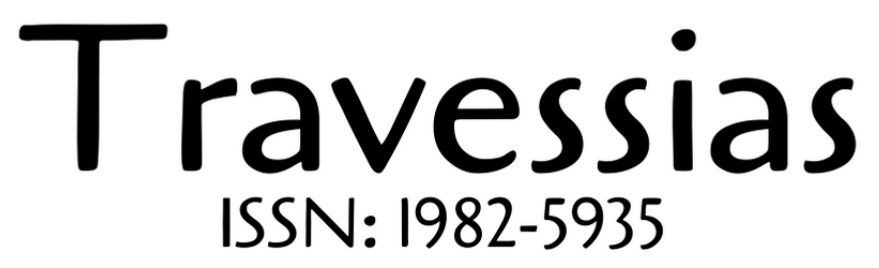

Direitos autorais distribuídos a partir da licença Creative Commons (CC BY-NC-SA - 4.0)

\title{
VER (OU/VIR) TORQUATO NETO
}

\author{
Renan Nuernberger - renannuernberger@gmail.com \\ Universidade de São Paulo, USP, São Paulo, SP, Brasil; https://orcid.org/0000-0002-0494-5517.
}

\begin{abstract}
RESUMO: A partir de duas diferentes versões do poema "vir ver ou/vir", este artigo propõe uma análise da poética de Torquato Neto, enfatizando sua singularidade dentro do panorama da poesia brasileira na década de 1970. Em primeiro lugar, se pretende observar o quanto a ausência de um livro autoral, organizado pelo próprio poeta, acabou reforçando certa instabilidade constitutiva de seu trabalho, cuja produção se dava por meio de diversas atuações - como letrista, jornalista, fotógrafo, ator, roteirista, etc. Por outro lado, apesar dessa multiplicidade, é preciso levar em consideração que o próprio Torquato sempre reivindicou a denominação de poeta ("mãe das artes"), o que obviamente baliza todas as outras atividades a partir dessa perspectiva específica. Assim, se Torquato pode mesmo ser entendido como um dos representantes de uma "nova sensibilidade dos não especializados", sua constelação orbita em torno dos problemas formulados pelos outros poetas, em especial as reflexões teóricas e as realizações artísticas dos poetas concretos da década de 1950 e 1960. Nesse sentido, a curiosa visualidade de "vir ver ou/vir" pode iluminar, em muitos aspectos, a relação de Torquato com os postulados concretistas, trazendo consequências para uma compreensão mais aprofundada da própria poesia concreta no início dos anos 1970.
\end{abstract}

PALAVRAS-CHAVE: Torquato Neto; poesia concreta; poesia marginal

\section{INTRODUÇÃO}

Na poética de Torquato Neto, a experimentação não se restringe ao uso inventivo da linguagem verbal, estilhaçando-se na livre exploração dos mais diversos códigos, amalgamados, por sua vez, na própria vivência errática do artista, cuja figura pública era índice constitutivo da "obra". Nesse sentido, tanto ou mais do que seus colegas tropicalistas, Torquato encarnou as ambições e os impasses estéticopolíticos de sua geração, animada pelas novas possibilidades criativas da cultura de massas, mas esfacelada, no plano individual e coletivo, pelo estreitamento de horizontes após a derrocada dos movimentos emancipatórios e/ou revolucionários que, em lugares diversos e com diferentes consequências, marcaram a passagem entre as décadas de 1960 e 1970.

Mais do que apontar a trajetória do poeta, do lirismo delicado de "Zabelê" ao manifesto (auto)derrisório de "Marginália" - parcerias com Gilberto Gil -, culminando na melancólica desesperança de "Três da madrugada" - parceria com Carlos Pinto -, valeria arriscar uma compreensão menos linear e, ao mesmo tempo, mais específica do modo de irradiação dessa poética: sem a ancoragem do livro, a escritura de Torquato forma uma espécie de constelação instável, cuja possível coesão é reconstituída pelo leitor/espectador a partir das relações que este estabelece entre letras de canções, artigos de jornal, roteiros de televisão, notas de diários, fotografias, poemas, etc. 
Ou seja, não há organização pré-estabelecida para o conjunto da obra, o que explica as diferenças editoriais entre as publicações póstumas, Os últimos dias de paupéria (1973), organizada por Ana Duarte e Waly Salomão, e os dois volumes de Torquatália (2004), organizados por Paulo Roberto Pires. No caso, o livro da década de 1970, lançado pouco depois da morte do poeta, se mostra mais aberto a essa indeterminação, já que a ausência de notas explicativas torna a experiência de leitura menos dirigida ${ }^{1}$. Por sua vez, a coleção mais recente, a despeito do inegável mérito de recuperar materiais importantes, acabou estabelecendo uma classificação mais estável, dividindo o trabalho do poeta a partir da articulação entre ordem cronológica e gênero textual - "inéditos de juventude", "primeiros manifestos tropicalistas", "cancioneiro", "poesia”, etc. -, o que pressupõe certo planejamento hierárquico, aspecto assinalado pelo próprio organizador na nota introdutória do primeiro volume (PIRES apud NETO, 2004, p.7-9).

De todo modo, independentemente das escolhas editoriais, a irradiação dessa poética constelar está entranhada na própria atuação pública de Torquato. Afinal, o poeta, que gozava de prestígio em muitos círculos culturais, nunca publicou um livro com seus poemas, preferindo se inserir, de maneira recorrente, em espaços de maior circulação, como as colunas de jornal, as revistas coletivas e as letras de música. Embora esse gesto seja compartilhado por muitos outros artistas de sua geração ${ }^{2}$, a despreocupação de Torquato Neto quanto ao livro autoral revela-se uma exceção, já que mesmo um poeta como Waly Salomão - tão múltiplo e underground quanto Torquato - publicou Me segura qu'eu vou dar um troço, em 1972, inaugurando um flanco em sua poesia que, nas décadas seguintes, se desenvolveria dentro dos livros.

Por outro lado, essa atuação de Torquato Neto remete à ambição dos poetas concretos, os quais, desde a década de 1950, já almejavam a inserção da poesia no cotidiano dinâmico da metrópole em desenvolvimento, projetando peças verbivocovisuais com os recursos de novas tecnologias da cultura de massa que alcançariam um público mais amplo. Entretanto, por mais que tenham produzido cartazes, móbiles e outros objetos, é inegável que o livro continuava sendo para os concretos um espaço

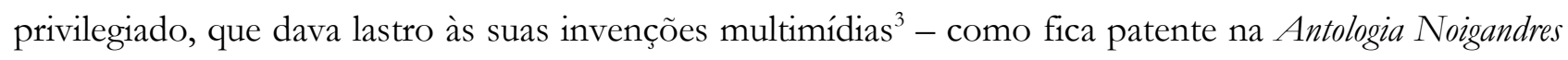

\footnotetext{
${ }^{1}$ Como observa o próprio Paulo Roberto Pires, essa indeterminação seria ainda maior na segunda edição de Os últimos dias de paupéria (1982): “Como Waly gostava de dizer, uma edição em ziguezague, que procura manter intocadas - e, aliás, consegue muito bem - as impressionantes convulsões internas de uma obra. Linearidade é um conceito que, propositalmente, não existe num livro que sequer tem suas quase quinhentas páginas numeradas” (PIRES apud NETO, 2004, p.7).

2 Para Heloisa Buarque de Hollanda, naquele "clima de fragmentação, desagregação e contradições, a intervenção cultural do pós-tropicalismo se faz múltipla e polivalente: os produtores 'atacam' em várias frentes, diversificando-se profissionalmente. Os autores intervêm indiferenciadamente em várias áreas da cultura de acordo com os espaços possíveis de serem abertos” (HOLLANDA, 2004, p.80).

${ }^{3}$ Isso é evidente, ainda hoje, no trabalho de Augusto de Campos. Em seu livro mais recente, Outro (2015), o poeta adaptou para a página uma série de peças pensadas inicialmente para plataformas digitais, sobretudo para o site da revista Errática. Segundo o próprio Augusto, "vários desses poemas - quadros querendo ser clips - perdem algo de sua intencionalidade na medida em que são ou formas estáticas, derivadas de animações digitais, ou projetos de clip-poemas pedindo movimento e som" (CAMPOS, 2015, p.9). Caberia perguntar, portanto: por que publicar esses clip-poemas em livro apesar da mencionada perda de "intencionalidade", se não pelo prestígio do suporte?
}

Travessias, Cascavel, v. 14, n. 2, p. 24-36, maio/ago. 2020.

http://www.unioeste.br/travessias 
(CAMPOS et al., 1962), que delineava todo o percurso do movimento do "verso à poesia concreta" até o chamado "salto participante". E mesmo os poetas marginais, na década de 1970, que - sob a égide de Torquato - construíam seus próprios espaços informais de circulação e fruição artística, mantiveram o livro, ainda que mimeografado, como objeto de mediação do contato entre autor e público ${ }^{4}$.

Em suma, mais do que a poesia da maioria de seus pares, a produção de Torquato escapa à catalogação estreita das páginas, extravasando em outros suportes, como discos, filmes em super-8 e na própria composição do personagem vampiresco, de cabelos longos e olhar entristecido, registrado em tantas fotografias. Entretanto, se, por um lado, esses materiais heterogêneos - imagens, textos, sons mantêm-se dispersos, sem uma hierarquização que os delimite, por outro, certas recorrências os coadunam, dando a ver um projeto que se debate, hesitando entre a exteriorização explosiva e o desejo de ensimesmamento ${ }^{5}$. Isso não significa que não existam modulações - de um primeiro período mais associado aos parâmetros da arte nacional-popular, de um momento propriamente tropicalista e, por fim, de uma radicalização underground -, apenas que essas modulações não são estanques, girando em torno de alguns motivos que, quando colidem, retornam transfigurados.

\section{VIR VER OU/VIR}

Como sugerido acima, a organização aberta de Os últimos dias de panpéria ressalta bem esse aspecto constelar: a intervenção belicosa dos artigos da "Geleia geral” reverbera na fragilidade íntima do diário "D’engenho de dentro"; os diversos rascunhos de poemas como "Go back" impedem a fixação de uma versão definitiva; a ausência de notas desloca as peças de seus contextos originais - o jornal, o roteiro, o frame -, nivelando-as num mesmo plano. De todo modo, é importante destacar que, a despeito de sua versatilidade - escritor, roteirista, articulista, ator, cineasta -, Torquato Neto sempre reivindicou a denominação de poeta. É este, afinal, quem aciona a constelação, pois, como se lê em tantas passagens, o poeta é “mãe das artes" (NETO, 1973, p.118).

\footnotetext{
${ }^{4}$ Essa mediação foi percebida por Cacaso, em ensaio sobre a poesia de Chacal: "Muito mais do que apresentar um livro, o poeta apresenta-se através dele, vale-se dele como se fosse um cartão de visitas. Seria o caso de perguntar: [...] Mais fácil e mais coerente não seria dispensar o cartão e partir logo para uma abordagem direta e viva? As contradições começam a se esboçar: ao propor uma quase coincidência entre a poesia e a vida, isso resultaria, no limite, no desaparecimento, por necessidade, da própria poesia. O simples ato de escrever já seria um afastamento da vida, e a circulação do livro, ainda que restrita e informal, só serviria para dar alguma generalidade a este distanciamento" (BRITO, 1997, p.24-25).

${ }^{5}$ Viviana Bosi observa que os últimos escritos de Torquato Neto são muitas vezes "pedaços picotados de poemas anteriores ora submetidos à intensificação do fragmento obsessivo, no espectro oposto da facilidade 'alegrinha' (também a se considerar...) aparente em outros poemas (como cara e coroa). O ímpeto de 'festa e comício' é contrabalançado pela confissão da solidão, a internação no sanatório, o anseio de morte, que pontuam a trajetória de Torquato, a vacilar entre o ardor do entusiasta procurando frestas no marasmo, e o desalento angustiado lutando consigo para não soçobrar - como se a alegria fosse uma resolução heroica e mesmo patética" (BOSI, 2015, p.47).
} 
O poeta é valorizado em sua capacidade de criação em sentido amplo, como matriz de múltiplas possibilidades no campo artístico. Ou seja, seu trabalho não se restringe ao verso ou mesmo à mancha gráfica do texto, incorporando muitas outras linguagens que ampliam seu raio de invenção. Essa ideia também comparece no poema - ou manifesto? ou carta? -, bastante conhecido, "Pessoal intransferível":

\begin{abstract}
Escute, meu chapa: um poeta não se faz com versos. É o risco, é estar sempre a perigo sem medo, é inventar o perigo e estar sempre recriando dificuldades maiores, é destruir a linguagem e explodir com ela. Nada no bolso e nas mãos. Sabendo: perigoso, divino, maravilhoso.

Poetar é simples, como dois e dois são quatro sei que a vida vale a pena etc. Difícil é não correr com os versos debaixo do braço. Difícil é não cortar o cabelo quando a barra pesa. Difícil, para quem não é poeta, é não trair sua poesia [...] (NETO, 1973, p.19).
\end{abstract}

Forjando uma intimidade geracional ("meu chapa"), o enunciador anseia que sua voz se faça presente, que seja escutada, como se não houvesse distância entre ele e seu interlocutor. No primeiro bloco textual, há um tom de conselho de amigo, encadeado num ritmo acelerado pelas repetições do verbo (“é”) e pela construção de um fraseado sintético (“Sabendo:”). Glosando a resposta de Mallarmé a Degas ${ }^{6}$ para subvertê-la, Torquato enfatiza não o poema, mas o poeta - aquele que inventa o perigo. Aqui o verbo "fazer" se torna autorreflexivo: o poeta (se) faz com seus atos e é justamente nesse fazer que se forma enquanto poeta, sendo o verso, ou qualquer outro material, a manifestação objetiva que dá a ver esse processo e se esgota na medida mesmo em que o realiza ("é destruir a linguagem e explodir com ela").

A “dificuldade", nesse caso, não está no "poetar", mas sim na sobrevivência física daquele que resiste à "barra pesada". Essa postura, de quem enfrenta o cotidiano sufocante a partir de uma mudança comportamental, aparece também em muitas das canções tropicalistas, como as duas citadas no poema, "Alegria, alegria", de Caetano Veloso, e "Divino Maravilhoso", de Caetano e Gil, trazendo um curioso ruído ao título: a vOz desse sujeito, "pessoal intransferível”, se forja na incorporação de outras vozes afins, reverberando um sentimento de mundo compartilhado por boa parte de sua geração. Na outra ponta, a alusão à poesia de Ferreira Gullar ${ }^{7}$ delimita essa partilha, definindo pelo avesso o que seria, para Torquato, um "poeta sem risco".

\footnotetext{
6 "Muitas vezes o grande pintor Degas me contou essa frase de Mallarmé, tão justa e tão simples. Degas às vezes fazia versos, e deixou alguns deliciosos. Mas constantemente encontrava grandes dificuldades nesse trabalho acessório de sua pintura. [...]. Um dia disse a Mallarmé: ‘Sua profissão é infernal. Não consigo fazer o que quero e, no entanto, estou cheio de ideias...'. E Mallarmé lhe respondeu: 'Absolutamente não é com ideias, meu caro Degas, que se fazem versos. É com palavras"' (VALÉRY, 2007, p.207-208).

7 Trata-se do poema "Dois e dois: quatro": "Como dois e dois são quatro/ sei que a vida vale a pena/ embora o pão seja caro/ e a liberdade pequena// [...]” (GULLAR, 2001, p. 171). Embora seja evidente a referência a Gullar, valeria localizar a publicação original desse poema antes de sua inclusão em Dentro da noite veloz, que engloba boa parte da produção do poeta de 1962 até 1975.
}

Travessias, Cascavel, v. 14, n. 2, p. 24-36, maio/ago. 2020. http://www.unioeste.br/travessias 
Por fim, não se pode ignorar que o jargão utilizado no poema - "risco", "inventar", "recriando" - é derivado, em grande medida, dos textos teóricos dos poetas concretos, para os quais um poema também "não se faz com versos". Há, no entanto, uma diferença patente: se, para o grupo Noigandres na década de 1950, a abolição do verso abria o poema para novas relações entre códigos verbais e nãoverbais, enfatizando a própria materialidade do signo $^{8}$, para Torquato - e tantos outros de sua geração , o próprio corpo é agenciado como signo, desestabilizando a formalização do poema. Ou, segundo Mario Cámara:

\begin{abstract}
Hasta aquí vimos un conjunto de operaciones por las cuales Torquato Neto usa conceptos concretos sobre los que ejerce un desplazamiento. Por otra parte, he señalado la creación de un protocolo corporal que oficia de enclave de una retórica vanguardista y una retórica contracultural y neorromántica. Se hace visible ahora que ese protocolo cumple dos funciones: desplaza el subjetivismo exacerbado de la vertiente flower power de la contracultura y quiebra cualquier tentación formalista. El cuerpo permite construir un entrelugar donde los códigos se enlazan (CÁMARA, 2011, p. 150).
\end{abstract}

Mesmo a apropriação da expressão "geleia geral”, usada por Décio Pignatari no editorial da última edição da revista Invenção em 1967, configura-se a partir desse deslocamento: se a poesia concreta se quer tão somente "medula \& osso", a tropicália, com afetuosa ironia, se assumiria parte também da "geleia geral brasileira", tratando até mesmo os procedimentos da poesia concreta sob uma nova clivagem $^{10}$ como na canção "Batmacumba", na qual a sintaxe espacial adquire, quando entoada, algo de encantamento mágico, a palavra-valise aglutina um super-herói dos quadrinhos ("Batman”) à celebração dos orixás (“Obá”) e a sonoridade onomatopaica, pelas consoantes oclusivas - $[\mathrm{b}],[\mathrm{t}],[\mathrm{k}]-$, indicia a presença do corpo no ritual percussivo (de quem “bate macumba”).

Não que os poetas concretos, naquele momento, estivessem engessados nos mesmos parâmetros da década de 1950. Ao contrário, todos - com cada vez maiores diferenças entre si - arriscavam reflexões

\footnotetext{
${ }^{8}$ Lê-se no "plano-piloto para poesia concreta": "ideograma: apelo à comunicação não-verbal. o poema concreto comunica a sua própria estrutura: estrutura-conteúdo. o poema concreto é um objeto em e por si mesmo, não um intérprete de objetos exteriores e/ou sensações mais ou menos subjetivas. seu material: a palavra (som, forma visual, carga semântica). seu problema: um problema de funções-relações desse material. fatores de proximidade e semelhança, psicologia da gestalt. ritmo: força relacional. o poema concreto, usando o sistema fonético (dígitos) e uma sintaxe analógica, cria uma área linguística específica - 'verbivocovisual' - que participa das vantagens da comunicação não-verbal, sem abdicar das virtualidades da palavra. com o poema concreto ocorre o fenômeno da metacomunicação; coincidência e simultaneidade da comunicação verbal e nãoverbal, com a nota de que se trata de uma comunicação de formas, de uma estrutura-conteúdo, não da usual comunicação de mensagens" (CAMPOS et al., 2006, p.216-217).

${ }^{9} \mathrm{O}$ texto foi, pouco depois, republicado com pequenas mudanças no volume Contracomunicação: “[...] certa vez um consagrado poeta nos disse: o arco não pode permanecer tenso o tempo todo um dia tem de afrouxar \& eu: na geleia geral brasileira alguém tem de exercer as funções de medula \& osso [...]” (PIGNATARI, 2004, p.29).

10 "Internacionalistas, os concretos trataram o desenvolvimento como positividade, passando por cima do fato da dependência, só explorando as virtualidades da forma [...]. Os tropicalistas, por não vincularem sua prática a nenhum esquema prévio de figuração do momento político, trataram o desenvolvimento, assim como o engajamento, como integrantes de suas produções. [...]. Dessa forma, o que nos concretos era um fim em si mesmo - a linguagem absolutizada -, nos tropicalistas não passava de ingrediente. Não hipertrofiando o valor dos procedimentos, problematizaram a produção mesma" (FAVARETTTO, 2000, p.54-55).
}

Travessias, Cascavel, v. 14, n. 2, p. 24-36, maio/ago. 2020.

http://www.unioeste.br/travessias 
apuradas sobre as potencialidades dos novos meios de comunicação, com genuíno interesse pela intervenção tropicalista na televisão, e relativizavam cada vez mais a distinção entre "cultura erudita" e "cultura de massas", sintetizando seus anseios de participação no mass media a partir do conceito, cunhado por Décio Pignatari, de produssumo - uma arte que fosse, simultaneamente, "produção" e "consumo". Tal ideia ganharia uma de suas formulações mais radicais na "Teoria da guerrilha artística", também proposta por Pignatari em 1967:

\begin{abstract}
Nada mais parecido com uma constelação do que a guerrilha, que exige, por sua dinâmica, uma estrutura aberta de informação plena, onde tudo parece reger-se por coordenação (a própria consciência totalizante em ação) e nada por subordinação. Em relação à guerra clássica, linear, a guerrilha é uma estrutura móvel, operando dentro de uma estrutura rígida, hierarquizada. $[\ldots]$

Nada mais parecido com a guerrilha do que o processo da vanguarda artística consciente de si mesma. Na guerrilha, tudo é vanguarda e todos os guerrilheiros são vanguardeiros. E cada mosquito. E cada árvore. E cada gesto. Só a guerrilha é de fato total (excluindo-se a atômica...). Constelações de liberdade sempre se formando (2004, p. 168-169).
\end{abstract}

Em suma, ainda que se afaste da poesia concreta pela presença desestabilizadora do corpo, o trabalho de Torquato Neto - em sua estratégia de "ocupar espaços" 11 - poderia ser lido como parte da "guerrilha artística" almejada por Pignatari ${ }^{12}$. Nesse ínterim, porém, a própria poesia concreta perde seu estatuto de "medula \& osso" e se torna mais um dos repertórios coordenados sem hierarquização pelo poeta. Em outras palavras, o que na teoria de Pignatari se mantém como amálgama da constelação - a poesia concreta enquanto estrutura ${ }^{13}$ - é pulverizado na ação de Torquato.

Com isso, seria possível explorar alguns artefatos do poeta, cujas qualidades, em suas variadas modulações, incorporam a verbivocovisualidade concretista, sem se restringir a ela. É o caso, por exemplo, do poema abaixo, impresso isoladamente no canto direito inferior da página em Os últimos dias de paupéria (NETO, 1973, p. 105):

\footnotetext{
11 “Isso também tem a ver com poesia, mãe das artes \& manhas em geral: antes ocupar o espaço e logo em seguida poetar conforme for. Na gaveta, baratas e velharias. Poesia, não.

Ocupar espaço, criar situações. Ocupa-se um espaço vago como também se ocupa um lugar ocupado: everywhere. E aguentar as pontas, segurar, manter. Ou, como em Teorema [de Pasolini], entrar e sair do filme. Tiro um sarro: vampiro [...].

Sem começo nem fim, mas mesmo assim: pelas brechas, pelas rachas. Buraco também se cava e a cara também se quebra. Mas cuidado com os psiquiatras [...].

Ocupar espaço: espantar a caretice: tomar o lugar: manter o arco: os pés no chão: um dia depois do outro" (NETO, 1973, p.39).

12 Em entrevista concedida a Régis Bonvicino em 1982, Pignatari confirma que "Torquato era um criador-representante da nova sensibilidade dos não especializados”. Disponível em: http://sibila.com.br/critica/torquato-neto-conversa-entre-deciopignatari-e-regis-bonvicino/8578 (Acesso em 23/11/2019).

13 "Já repararam como as toupeiras lineares do sistema concedem em dar importância teórica à poesia concreta, para logo em seguida reclamar de sua falta de 'resultados'? Oportunismo do sistema em busca de equilíbrio: como milhafres no restolho ou albatrozes na esteira alimentar de um barco, acreditam um dia suprir a 'lacuna', realizando as 'obras' que os poetas concretos teriam deixado de realizar! Incapazes de perceber estruturas, não percebem que a 'obra' da poesia concreta é tudo: confundese com seus próprios percursos com os seus roteiros, com seu processo de constelação móvel” (PIGNATARI, 2004, p.169170).
} 
Contraposto ao vazio do centro da página, a peça poderia ser entendida, inicialmente, como uma espécie de poema concreto deslocado, já que não respeita a centralidade da quadrícula ${ }^{14}$. Em seguida, é possível perceber que a expressão dá título ao texto que aparece nas páginas seguintes - "a coroa do rio poti em teresina lá no piauí (...)” (p. 107) -, composição que se repete no prólogo do filme Terror da Vermelha, dirigido por Torquato em 1972. Não é difícil perceber como essa dupla função - poema autônomo, título de texto - sintetiza as oscilações de poética de Torquato, uma vez que a expressão não se fixa num lugar estável.

Essa oscilação é também estrutural, inspirando uma leitura polivalente: um sintagma virtualmente circular ("vir ver ou vir ver ou vir..."), uma paródia da máxima latina (veni, vidi, vici), três verbos no infinitivo ("vir", “ver", “ouvir”). O poema parece instruir o leitor a se aproximar ("vir"), experimentá-lo sensorialmente, acoplando dois sentidos simultâneos, o visual e o auditivo. O artefato é acionado por essa interação entre "ver" e "ouvir", numa espécie de simultaneidade disjuntiva: a visualidade destaca a quebra que torna o texto circular ("ou/ vir") enquanto a vocalização sugere o contínuo que remete ao significado do terceiro verbo (“ouvir").

Essa interação lúdica entre olho e ouvido também foi bastante explorada pelos poetas concretos, em peças como "branco", de Haroldo de Campos, ou "vai e vem” de José Lino Grünewald. Sobre esta última, Max Bense sinaliza:

\footnotetext{
"Vai" e "vem" têm o caráter sígnico de um índice, eles dizem precisamente que é "ele" que vai e vem. Também o "e" que liga "vai" e "vem" funciona como índice. A disposição visual permite que se leia o conjunto de índices da direita para a esquerda, da esquerda para a direita, de cima para baixo, de baixo para cima e em círculo. Desse modo a superfície do texto expressa o esquema do "vai e vem", do "acima e abaixo", do "eterno retorno". O conjunto dos índices representa em sua totalidade visual um ícone que se relaciona tanto com o mundo particular do texto como objeto quanto com um evento do mundo exterior (BENSE, 2009, p. 78).
}

Pela proximidade paronomástica, "vir ver ou/vir" parece ecoar "vai e vem" - publicado originalmente em 1959 na revista Noigandres -, uma vez que ambos articulam um conjunto de índices que constituem um ícone: de um lado, no poema de Grünewald, a correspondência interna entre o verbal e

\footnotetext{
14 “'Todos os poemas da fase matemática - o estado 'mais avançado' do concretismo antes do salto 'conteudista' à lírica participante - utilizam a forma da quadricula. Ao dispor os signos de um modo regular, as formas geométricas quadriculares (sintéticas e simultâneas) pretendem substituir as disposições lineares do verso (sucessivas e recursivas)" (AGUILAR, 2005, p.203).
} 
o visual, reforçada pelo conectivo "e", que aponta para o próprio movimento de ir e vir; do outro, no poema de Torquato, a disjunção entre visual e sonoro, reforçada pelo conectivo “ou”, cujo sentido depende da ênfase do espectador em ver ou ouvir. De todo modo, essa comparação, talvez arbitrária, torna-se mais consistente tendo-se em vista uma das versões do poema de Torquato publicada na revista Navilouca (1974), na qual o maior cuidado com a visualidade, pensada a partir de uma relação problematizada com a grade em quadrícula, é articulado a um novo elemento irruptivo, que ocupa o espaço que estaria em branco na página:

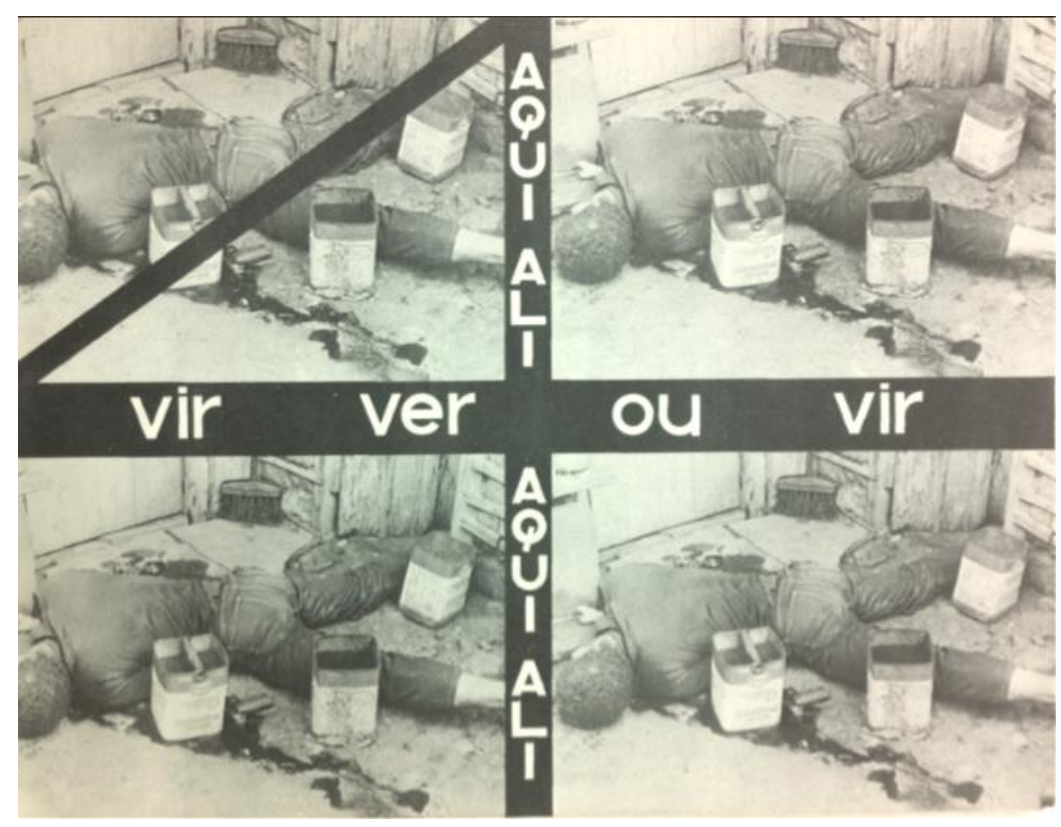

Agora em formato de cruz, o poema possui dois eixos verbais: um horizontal, que recupera linearmente o material já abordado, mas em letras minúsculas ("vir ver ou vir"), outro vertical, composto por dêiticos em caixa alta (“AQUI ALI AQUI ALI”). A quadrícula, nesse caso, se faz pelo preenchimento virtual do espaço vazio de código verbal, quase como um negativo de "vai e vem" de José Lino Grünewald:
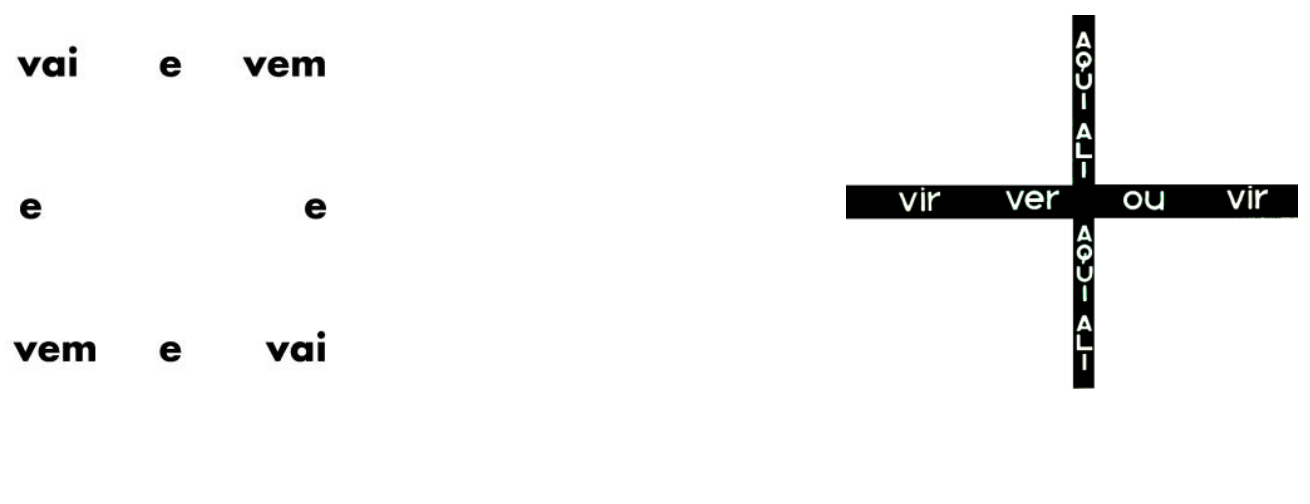

Travessias, Cascavel, v. 14, n. 2, p. 24-36, maio/ago. 2020. http://www.unioeste.br/travessias 
O poema de Torquato, entretanto, não se restringe a esses dois eixos verbais. Dispostas em segundo plano, encontram-se quatro repetições de uma mesma fotografia: um rapaz, aparentemente morto, caído entre latas de querosene num ambiente sujo e desorganizado. Não há nenhum indício sobre o contexto da foto - seria uma encenação dirigida pelo próprio poeta? um recorte de notícia policial? o frame de algum filme marginal? - o que oculta a origem da imagem, mantendo, sem mediação clara, a violência da cena, seja ela ficcional ou factual.

Essa indeterminação da imagem é ressaltada pelos pequenos deslocamentos de cada uma das quatro fotos, uma vez que todas as reproduções são ligeiramente distintas. Numa espécie de "jogo dos sete erros" perverso, também sinalizado pelo corte na imagem do quadro superior esquerdo - como um take eliminado na edição final de um filme? -, o poema convida o espectador a "ver" cuidadosamente aquela cena: o que aconteceu àquele rapaz? o líquido derramado é sangue ou querosene? a vassoura no fundo do cômodo revela alguma coisa?

Os dêiticos antinômicos ("aqui", "ali”) geram ainda mais indeterminação, já que impedem uma localização espacial precisa do evento. Se, como sugere Mario Cámara, esses dêiticos "en el contexto de la dictadura, parecen adquirir otro sentido, como si la violencia estuviera 'aquí, allí y en todas partes" (CÁMARA, 2011, p.185), não se pode esquecer que a própria estrutura visual do poema sugere um recorte bastante específicos dentro desse "contexto", ligado à situação de precariedade material e risco eminente de execução. Quer dizer, de certa maneira, a imagem desmente o texto - ou, pelo menos, o relativiza -, reforçando ainda mais a disjunção formalizada no poema: entre o eixo horizontal (“AQUI ALI") e a reprodução levemente deslocada da fotografia, os referenciais de observação se desestabilizam, de modo que, não sendo possível definir claramente a distância entre o olhar e a cena, o próprio lugar do leitor diante dessa matéria é questionado.

Tal qual a disjunção de "vir ver ou/vir" sugeria uma atitude de maior aproximação ("vir") ou algum afastamento ("ver"), "AQUI ALI" provoca o observador, exigindo que ele, com as poucas informações disponíveis, se posicione com relação ao acontecimento retratado. Por seu turno, as pequenas variações entre as quatro fotografias mantêm no centro da imagem esse mesmo corpo abandonado em meio à sucata, num jogo de repetições que parece, ao mesmo tempo, enfatizar o horror antevisto na cena e dissolvê-lo na banalização de sua exposição prolongada.

Há nisso, talvez, algo daquele "realismo traumático", estudado por Hal Foster em certas obras de Andy Warhol, segundo o qual a repetição: 
caso o real rompe o anteparo da repetição. É uma ruptura não tanto no mundo quanto no sujeito - entre a percepção e a consciência de um sujeito tocado por uma imagem (FOSTER, 2014, p.128129).

Enquanto um dos verbos sugere que o espectador se aproxime do poema ("vir"), aguçando sua curiosidade, a imagem repetida, em sua dubiedade, pode também refratá-lo, por repulsa e/ou desconfiança. O agenciamento do corpo, assim, adquire outra conotação, deslocada por esse indivíduo anônimo e aparentemente morto. Sua presença física contrasta com a lógica asséptica da estruturaconteúdo autorreferente dos eixos verbais, cuja experiência sensorial (“vir ver ou/vir aqui ali”) é, a um só tempo, ressaltada e questionada pela repetição da imagem.

\section{CONSIDERAÇÕES FINAIS}

Ao preencher o branco da página, fundamental para a lógica concretista, com a densidade desse corpo mortificado, o poema de Torquato desrecalca a violenta mudança de sinal que o impulso modernizador - pensado, na década de 1950, como processo de democratização emancipatória - adquiriu após o golpe de $1964^{15}$. Desse modo, os aspectos concretistas da poética de Torquato Neto parecem aqui, ambiguamente, valorizados e relativizados. Mesmo que a montagem com elementos não-verbais já fosse explorada pelos poetas concretos - basta pensar nos popcretos de Augusto de Campos -, é preciso destacar a especificidade de "vir ver ou/vir", cuja "sujeira" não se restringe a um efeito superficial da imagem, estando no cerne do próprio procedimento de justaposição da foto sensacionalista com o objeto verbivocovisual.

Nesse sentido, a observação de Max Bense sobre a dupla natureza do ícone em "vai e vem" é ainda mais potente com relação ao poema de Torquato: enquanto os eixos verbais confluem para um "mundo particular do texto como objeto", as fotos parecem apontar para um "evento do mundo exterior”; por seu turno, o próprio processo de repetição da imagem opera em termos muito semelhantes ao dos eixos verbais, combinando-se numa estrutura em quadrícula que aponta para si mesma, sem com isso apagar de todo o choque com relação à violência da cena - que, ao contrário, parece ressignificar as ações sugeridas pelo texto do poema ("vir ver ou/vir").

\footnotetext{
${ }^{15}$ Sobre a poesia concreta após o golpe civil-militar, escreve Iumna Maria Simon: “a experiência progressiva e concreta da modernização acentuou a necessidade de a produção cultural apresentar posição crítica face a uma realidade que já não comportava idealizações. Progresso industrial, avanço tecnológico, planejamento total e racional da vida são no fim das contas chavões vazios se forem meramente vinculados à 'fisiognomia' de uma época, e é o que eles se tornaram quando à modernização sonhada sobreveio a modernidade da pobreza, da desigualdade social, da privatização da esfera pública, dos mecanismos de exclusão próprios a uma sociedade de consumo sem generalização do consumo. Quem vai refutar aquele 'programa geral de beleza' será agora a realidade miserável e moderna do presente, pois todos os termos pelos quais a modernidade fora idealizada se desmancham face aos resultados concretos dessa modernização truncada" (SIMON, 1990, p.134-135).
}

Travessias, Cascavel, v. 14, n. 2, p. 24-36, maio/ago. 2020.

http://www.unioeste.br/travessias 
Sem poder esgotar a instabilidade dessa forma em curto-circuito, valeria aqui uma última indagação. Como vimos, Torquato Neto costuma enfatizar muito a escuta, não apenas nas canções - nas quais essa dimensão é evidente -, mas na própria interpelação direta a seu interlocutor como em "Pessoal intransferível". Aqui, novamente, a sugestão de "vir", "ver" e "ou/vir", num gesto que aglutina o transbordamento imediato dos sentidos ("ver" e "ouvir"), bem como a meditação reflexiva ("vir" e depois "vir" de novo), convida o espectador a uma aproximação - não mais com o poeta, mas com o próprio poema, lugar onde essas tensões se fazem presentes. Bem, esse presumido espectador se aproxima, observa, analisa, mas será capaz de ouvir a cena, seus ruídos e seus silêncios, para além do material sonoro das palavras?

\section{REFERÊNCIAS}

AGUILAR, Gonzalo. Poesia concreta brasileira: as vanguardas na encruzilhada modernista. Tradução de Regina Aida Crespo e Rodolfo Mata. São Paulo: Edusp, 2005.

BENSE, Max. Inteligência brasileira: uma reflexão cartesiana. Tradução de Tércio Redondo. São Paulo: Cosac Naify, 2009.

BOSI, Viviana. Torquato Neto: “Começa na lua cheia e termina antes do fim”. Literatura e Sociedade, São Paulo, SP, n. 19, p.32-56, 2015. Disponível em:

http://www.revistas.usp.br/ls/article/view/97175. Acesso em: 03 jun. 2020.

BRITO, Antonio Carlos de. Tudo da minha terra. In: BRITO, Antonio Carlos de. Não quero prosa. Organização de Vilma Arêas. Campinas: Ed. UNICAMP; Rio de Janeiro: Ed. UFRJ, 1997. p. 18-43.

CÁMARA, Mario. Cuerpos paganos: usos y efectos de la cultura brasileña, 1960-1980. Buenos Aires: Santiago Arcos Editor, 2011.

CAMPOS, Augusto de. Outro. São Paulo: Perspectiva, 2015.

CAMPOS, Augusto de; CAMPOS, Haroldo; PIGNATARI, Décio. Teoria da poesia concreta: textos críticos e manifestos, 1950-1960. São Paulo: Duas Cidades, 1975.

CAMPOS, Augusto de; CAMPOS, Haroldo de; PIGNATARI, Décio; GRÜNEWALD, José Lino; AZEREDO, Ronaldo. Antologia Noigandres: do verso à poesia concreta. São Paulo: Massao Ohno, 1962.

FAVARETTO, Celso. Tropicália: alegria, alegoria. Cotia-SP: Ateliê, 2000.

FOSTER, Hal. O retorno do real: a vanguarda no final do século XX. Tradução de Célia Euvaldo. São Paulo: Cosac Naify, 2014.

GRÜNEWALD, José Lino. Escreviver. São Paulo: Perspectiva, 2008.

GULLAR, Ferreira. Toda poesia. Rio de Janeiro: José Olympio, 2001. 
HOLLANDA, Heloisa Buarque de. Impressões de viagem: CPC, vanguarda e desbunde: 1960/70. Rio de Janeiro: Aeroplano, 2004.

NETO, Torquato. Os últimos dias de paupéria. Organização de Ana Duarte e Waly Salomão. Rio de Janeiro: Eldorado, 1973.

NETO, Torquato. Os últimos dias de paupéria. Organização de Ana Duarte e Waly Salomão. São Paulo: Max Limonad, 1982.

NETO, Torquato. Torquatália: do lado de dentro. Organização de Paulo Roberto Pires. Rio de Janeiro: Rocco, 2004.

NETO, Torquato. Torquatália: geleia geral. Organização de Paulo Roberto Pires. Rio de Janeiro, Rocco, 2004.

PIGNATARI, Décio. Contracomunicação. Cotia-SP: Ateliê, 2004.

SALOMÃO, Waly; NETO, Torquato (org.). Navilouca: almanaque de aqualoucos. Rio de Janeiro: Edições Gernasa, 1974.

SIMON, Iumna Maria. Esteticismo e participação: as vanguardas poéticas em contexto brasileiro (19541969). Novos Estudos CEBRAP, São Paulo, SP, n. 26, p. 120-140, março de 1990.

VALÉRY, Paul. Poesia e pensamento abstrato. In: VALÉRY, Paul. Variedades. Tradução de Maíza Martins de Siqueira. São Paulo: Iluminuras, 2007. p. 201-218. 


\title{
Title
}

See (come/hear) Torquato Neto.

\begin{abstract}
This article intends to understand Torquato Neto's poetics stem from two different versions of a same poem ("vir ver ou/ vir"), emphasizing his singularity in the Brazilian poetry of the 1970's. Beforehand, it seeks to observe a constitutive instability of Torquato's work, evidenced by the lack of an individual book, on the one hand, and on other by his multifaceted practices - such as songwriter, journalist, photographer, actor, scriptwriter, etc. In spite of this versatility, however, it should consider that Torquato Neto always claims himself as poet ("mother of arts"), which obviously affects all other activities. Moreover, if Torquato's constellation can be read as "unskilled new sensibility", it's also clear in his work the impact of Brazilian concrete poets due to their theoretical reflections and artistic achievements on 1950's and 1960's. Therefore, the unusual visuality of this poem ("vir ver ou/vir") can enlighten the relationship between Torquato Neto and concretist premises, bringing implications for understand the own concrete poetry on 1970's.
\end{abstract}

\section{Keywords}

Torquato Neto; concrete poetry; marginal poetry.

Recebido em: 03/06/2020.

Aceito em: 27/08/2020. 